\title{
Mídia, segurança pública e representações sociais*
}

Maria Stela Grossi Porto

Introdução

Centrada na perspectiva sociológica de compreensão dos possíveis efeitos da atuação midiática no estabelecimento de políticas de segurança pública e limitando minhas observaçōes e exemplos ao Distrito Federal, explicito, inicialmente, a ideia que pretendo defender: as mídias constituem, nas modernas democracias contemporâneas, um dos principais produtores de representaçôes sociais, as quais, para além de seu conteúdo como falso ou verdadeiro, têm função pragmática como orientadoras de condutas dos atores sociais. Sendo assim, faz sentido argumentar em favor da relevância do tema como subsídio para a formulação de políticas para a área, não por serem as representaçôes sinônimo de verdade, mas por se constituírem em veículos privilegiados de crenças, valores e anseios de distintos setores da sociedade.

Não sendo a mídia minha área de reflexão teórica ou campo de pesquisa empírica, esta incursão no tema decorre, pois, de sua centralidade como ator social nas modernas democracias. Sob esse aspecto, Muhlmann (2008, p. 19), em sua apresentação e comentários sobre os textos de Robert E. Park, recentemente publicados em francês, estabelece relação estreita entre imprensa e democracia, ressaltando, igualmente, o fato de esse autor - que foi jornalista antes de se notabilizar como representante por excelência da Escola de Chicago - ter elaborado análises sobre o jornalismo moderno que cer-

\footnotetext{
* A versão inicial deste texto foi apresentada durante o II Encontro do Fórum Brasileiro de Segurança Pública, como parte da mesa-redonda "Mídia e segurança pública“, em março de 2008, em Recife, e resulta de pesquisa apoiada pelo CNPq.
} 
1. Grifos em itálico retirados por Muhlmann das "Notas autobiográficas" de Park. Muhlmann esclarece que as notas foram ditadas por Park à sua secretária, na Universidade de Fisk. Encontradas entre seus papéis após sua morte, foram organizadas por E. Hughes e publicadas no volume 1 de Race and culture: the collected papers of R. E. Park, Glencoe, Illinois, The Free Press, 1950.

2. Como o leitor deve ter notado, os conceitos de comunicação e de mídia estão aqui tratados de modo mais ou menos intercambiável. Decorrência talvez da multiplicidade de sentidos do objeto de que tratam. Algumas precisões se fazem, entretanto, necessárias. Para apontá-las, valho-me de distinção proposta por Lima: "A comunicação cujo campo de estudos nos interessa é aquela que aparece tardiamente na história da humanidade e se constitui numa das importantes características da humanidade. Vale dizer, a comunicação que se distingue da comunicação humana stricto sensu pelo uso de tecnologias específicas e pelo surgimento de instituições. Contemporaneamente, é aquela a que se convencionou chamar meios de comunicação de massa (mass midia) ou mídia" (2001, p. 25, grifos do autor). tamente "merecem, por sua originalidade, pertinência e precisão, espaço de destaque na cultura geral do leitor que se interessa pela evolução das democracias midiáticas" (os grifos são meus). Nos dizeres de Muhlmann (cf. Idem, p. 20), Park concebia o saber do sociólogo, qualificado de super-repórter, como um aprofundamento do saber do jornalista, permitindo, da mesma forma, aliás, que a filosofia, melhor "compreender a natureza e a função des-

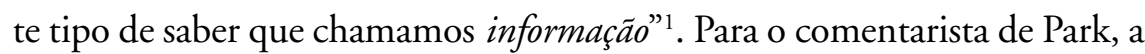
imprensa é foco de intensa visibilidade sobre a cidade, além do que a ênfase de Park no enfoque cultural da imprensa faz com que ele "represente uma posição particularmente fecunda nos trabalhos sobre a mídia, escapando da dicotomia que James Carey expôs brilhantemente em seu livro de 1989 desde então um clássico da sociologia da comunicação -, Comunication as Culture" (Idem, p. 23).

Essa dicotomia refere-se a duas grandes correntes, não totalmente excludentes: a primeira concebe a mídia como instrumento de transmissão de informação e a segunda considera que a comunicação midiática é forma de vivência cultural. Nos termos de Carey:

Comunicação é o processo através do qual mensagens são transmitidas e distribuídas no espaço para controle das distâncias e das pessoas [...] comunicação é o processo simbólico por meio do qual a realidade é produzida, mantida, reparada e transformada" (Carey, 1973, p. 3)².

Outra forma de pontuar essa dicotomia seria distinguindo as abordagens funcionalistas e sistêmicas, a partir do modelo matemático da informação, elaborado por Norbert Wiener, Claude Shannom e Warren Weaver em 1949 (cf. Weaver apud Cohn, 1987), daquelas das teorias críticas, cujos principais representantes são a Escola de Frankfurt (cf. Wolf, 1995) e os Estudos Culturais. A Escola de Frankfurt situa as reflexôes sobre os meios de massa no contexto da chamada indústria cultural (Horkheimer e Adorno), da reprodutibilidade técnica (Benjamim) e da unidimensionalidade (Marcuse) (cf. Wolf, 1987). Os Estudos Culturais, marxistas ou interacionistas simbólicos, de Birmingham na Inglaterra e do midwest norte-americano, veem a comunicação menos como meios e mais como formas de expressão cultural.

Em outra vertente, poder-se-ia mencionar as teorias que, não caracterizando a comunicação em sentido amplo como ciência propriamente dita, e, portanto, como um campo teórico autônomo, vão torná-la dependente de 
outras disciplinas científicas, como a sociologia, a antropologia, a semiologia, a linguística ou a filosofia, entre outras. Ou reconhecer de modo mais sistematizado, com Wolton, que a comunicação é um campo de pesquisa no qual se distinguem três polos: o primeiro, na interface com as neurociências; o segundo, na interface com as ciências cognitivas; o terceiro, centrado nas ciências humanas e sociais, levando o autor a concluir que "a investigação sobre comunicação é, por natureza, uma investigação interdisciplinar. Há, por um lado, temas verticais que correspondem a cada um desses polos, e, por outro, questôes transversais que encontramos em cada um desses polos" (Wolton, 2004, p. 484, grifos do autor). Entre esses temas e questôes, poder-se-ia dizer, complementando Wolton, estão aqueles ligados a outro enfoque, o que trata a comunicação e, sobretudo, a comunicação de massa, ou os meios, em termos de emissor/receptor, abrindo espaços para as múltiplas abordagens centradas na questão da interação entre ambos, nas distinções entre público, opinião pública e massa, passividade ou interatividade dos distintos receptores. Receptores que caracterizariam os sujeitos e/ou indivíduos da linguagem sociológica e que permitiriam estabelecer a ponte com a teoria das representaçóes sociais. Finalmente, no tratamento teórico da mídia, e sem com isso revelar pretensōes de exaustividade, caberia lugar de destaque aos já mencionados Estudos Culturais, que vão abordar a mídia no âmbito das dimensões culturais da comunicação (cf. Johnson, 2000), aproximando-se do campo sociológico, em sua vertente da sociologia compreensiva. Uma vez mais, Park mostra-se relevante:

Pensar os produtos midiáticos, e sobretudo jornalísticos, como a expressão de uma cultura era a grande questão para Robert Park. Mas sem jamais fixar a reflexão em um determinismo cultural que desresponsabilizaria os jornais. Estes são formas culturais que alimentam reflexivamente a cultura coletiva, agindo sobre ela" (Muhlmann, 2008, p. 23).

Esse breve e incompleto panorama que situa teoricamente o campo midiático ${ }^{3}$ permite que o texto se volte, então, às questões centradas nas relações entre mídia e segurança pública, pela ótica da teoria das representações sociais.

Para Patrick Champagne (1993), a mídia não apenas apresenta mas também representa a realidade da qual trata. Acatar tal afirmação implica atribuir à teoria das representações sociais potencial explicativo privilegiado para a compreensão da mídia e para o entendimento da forma como esta constrói,
3. Para outras análises sobre paradigmas e enfoques do campo midiático, ver também Proulx (1995); Peralva e Macé (2002); Wieviorka (2005) - estes últimos discutindo, sobretudo, o caráter mais autônomo ou mais dependente da mídia diante de outras determinaçōes da vida coletiva. Conferir, ainda, Ramos e Paiva (2007); Revista da USP(1991); Comunicação e Política (1995), número especial sobre "Mídia, drogas e criminalidade". 
reconstrói e seleciona fatos sociais por meio de narrativas, constituindo esses mesmos fatos em eventos/acontecimentos que, pelas significações e prioridades a eles atribuídas, chegam até a sociedade na condição de notícia.

Tratando-se das relações mídia/segurança pública, parece incontornável abordar também a questão da violência, cujo grau de crueldade de algumas de suas manifestações tem pautado não apenas a mídia dita sensacionalista, mas o conjunto dos meios.

Para alguns, a violência seria percebida como geradora do caos e da tragédia urbanos que caberia à segurança pública eliminar; para outros, é tida também como resultado do modus operandi dessa mesma segurança e, particularmente, das polícias que contribuiriam, desse modo, para reproduzir aquilo que seriam supostamente encarregadas de combater, reduzir, eliminar; constatação que põe a nu a tensão constante entre a articulação de lei e ordem sem ferir os direitos humanos, desafio maior das sociedades democráticas, no interior das quais os meios de comunicação de massa reivindicam papel cada vez mais hegemônico, tanto na dimensão material, leia-se econômica, como simbólica ou ideal, leia-se cultural.

Entre mitos, verdades e equívocos, parece pertinente supor que violência e segurança pública passaram a compor, neste mundo contemporâneo de riscos e incertezas, um par conceitual a partir do qual a violência é o fantasma cada vez mais presente que afronta e põe em risco a segurança.

Constituir o binômio mídia/segurança pública como objeto de análise significa refletir sobre o fato de que cada um dos polos do binômio constrói a realidade social por meio dos sentidos e das narrativas pelos quais representam a "realidade" da violência e a violência como realidade. Em outras palavras, se a realidade é construída, apresentada, representada por meio de narrativas e imagens de guerra ou de paz, os efeitos sobre possíveis formas de orientação de condutas dos atores sociais serão igualmente distintos:

[...] A informação "transformada em imagens" produz um efeito de dramatização suscetível de suscitar muito diretamente emoçôes coletivas. [...] as imagens exercem um efeito de evidência muito poderoso: mais do que o discurso, sem dúvida, elas parecem designar uma realidade indiscutível; mesmo que sejam, igualmente, o produto de um trabalho mais ou menos explícito de seleção e de construção (Champagne, 1993, p. 62).

A natureza das relações mídia/segurança pública é complexa, porque tensa e contraditória, por vezes, consensual e cúmplice, por outras. Essas 
relaçōes, por obedecerem a formações discursivas diferentes, são realidades não acabadas em si mesmas e conformam um campo em constante tensão e crise. Colocadas frente a frente, mídia e segurança pública têm afinidades, e ao mesmo tempo muito se estranham.

\section{Mídia e representações sociais}

$\mathrm{Na}$ argumentação sobre a utilização da teoria das representações sociais como subsídio à elaboração de políticas públicas, gostaria de citar algumas frases que, repetidas à exaustão nos noticiários de jornais e telejornais, nas revistas, em conversas, ganham estatuto de verdade, transformando-se em afirmaçōes não contestadas, cujo grau de evidência é pensado como dispensando demonstração.

1. A violência no Brasil é um fenômeno que vem, nos últimos anos, crescendo sistematicamente e não dá mostras de retroceder.

2. Embora existente no espaço rural, é um fenômeno urbano, característico das grandes cidades.

3. A pobreza e a miséria são algumas das causas mais imediatas da violência.

4. A instituição familiar está em crise, provocando desagregação moral, enfraquecimento dos valores e violência.

5. A entrada da mulher no mercado de trabalho é responsável pela desestabilização da família e, em consequência, da sociedade.

6. A religião perdeu importância como mecanismo de controle social, e sem esse freio instaura-se o vale-tudo a partir do qual se mata e se morre por um tênis, um pedaço de pão, uma bicicleta.

Não pretendo voltar a cada uma dessas afirmações e sentenciar sobre seu caráter falso ou verdadeiro. O conteúdo para a reflexão é de outra natureza: independentemente de sua condição de falsas ou verdadeiras, o que importa ressaltar é que, por força de repetição, tais afirmaçōes passam a fazer parte do imaginário popular. Uma vez constituídas como "verdade", informam condutas e comportamentos de atores sociais.

De outra parte, ditados, provérbios, valores e crenças inseridos nessas afirmaçôes formam o conteúdo por excelência do que chamamos representações sociais, noções por meio das quais os indivíduos buscam se situar no mundo, explicá-lo e apreender sua maneira de ser.

Como ensina Jodelet: 
Frente a esse mundo de objetos, pessoas, acontecimentos ou ideias, não somos (apenas) automatismos, nem estamos isolados num vazio social: partilhamos esse mundo com os outros que nos servem de apoio, às vezes de forma convergente, outras pelo conflito, para compreendê-lo, administrá-lo ou enfrentá-lo. Eis por que as representaçōes são sociais e tão importantes na vida cotidiana. Elas nos guiam no modo de nomear e definir conjuntamente os diferentes aspectos da realidade diária, no modo de interpretar esses aspectos, tomar decisóes e, eventualmente, posicionar-se frente a elas de forma defensiva (2001, p. 17).

E conclui a autora: a representação social "é uma forma de conhecimento, socialmente elaborada e partilhada, com um objetivo prático, e que contribui para a construção de uma realidade comum a um conjunto social" (Idem, p. 22).

Interrogar a realidade a partir do que se diz sobre ela, utilizando-se da categoria de representações sociais, significa assumir que elas:

a) embora resultado da experiência individual, [...] são condicionadas pelo tipo de inserção social dos indivíduos que as produzem; b) expressam visões de mundo objetivando explicar e dar sentido aos fenômenos dos quais se ocupam, ao mesmo tempo que, c) por sua condição de representação social, participam da constituição desses mesmos fenômenos; d) em decorrência do exposto em "b", apresentamse, em sua função prática, como máximas orientadoras de conduta; e) em decorrência do exposto em "c", admitem, nos termos de Michaud (1996), a existência de uma conexão de sentido (solidariedade) entre os fenômenos e suas representações sociais, que, portanto, não são nem falsas nem verdadeiras, mas a matériaprima do fazer sociológico (Porto, 2002).

Relevante reter da discussão é o fato de que neste mundo complexo, plural, fragmentado e, sobretudo, desigual, característico da modernidade, os indivíduos não detêm, de modo igualitário, o mesmo potencial de produção de sentidos, explicação e enfrentamento do mundo, na forma das representaçôes sociais, de que nos fala Jodelet. Pelo contrário, apenas alguns indivíduos, grupos ou setores da sociedade se constituem em protagonistas desse processo. Os demais, que formam, de fato, a maioria, apenas consomem conteúdos (normas, valores etc.) que não produziram. Ora, poucos deixarão de admitir que a mídia, em suas diferentes facetas, mas com claro predomínio dos meios televisivos, tem protagonizado de modo crescente essa função pragmática de "explicar o mundo" e produ- 
zir significado para fatos e acontecimentos sob a forma de representações sociais.

Ao pautar uma matéria, a mídia, ao mesmo tempo que apresenta e representa determinados acontecimentos, mediados por sua versão dos fatos, está silenciando outros.

Antes de se concluir por uma intenção maquiavélica da mídia, com o premeditado objetivo de distorcer ou ocultar fatos, vale ressaltar que está em questão, de um lado, esse efeito de evidência acima mencionado, o qual constrói a notícia como realidade; de outro, o fato de a mídia ser um campo de lutas, conflitos, interesses, concorrências, de busca por posiçōes e disputa por hegemonia, que se expressam interna e externamente ao campo (cf. Bourdieu, 1996). Internamente, a concorrência entre as grandes cadeias de empresas midiáticas não se situa unicamente na dimensão das disputas econômicas, mas também, e sobretudo, na disputa da produção simbólica. É nessa dupla dimensão material e simbólica que se joga o jogo da luta por hegemonia, considerando que está em questão uma mercadoria grandemente perecível, ou seja, a notícia.

Não partilho dos veredictos que, assumindo a mídia como quarto poder, diabolizam-na ou, ao contrário, divinizam-na, excluindo completamente o potencial de conhecimento, atuação e escolha dos atores sociais, os quais, como afirma Giddens (2003), são sujeitos com capacidades reflexivas e cognoscentes; fazem escolhas, ainda que sejam relativas, pois que submetidas e articuladas às desigualdades materiais e simbólicas e aos jogos de poder vigentes nas sociedades.

Isso posto, é no jogo de poder desse campo permeado por tensões, confrontos e acordos que os diferentes meios disputam o espaço midiático e constroem sua especificidade; buscam fazer a diferença, definir seu peso relativo em meio a um espaço de grande homogeneidade, a qual está situada em dois níveis: o do conteúdo - as fontes são quase sempre as mesmas e só ganha relevância midiática o que já for pautado como notícia - e o da forma - há todo um aparato de linguagem, de rotinas produtivas do jornalismo, de economia do tempo, do espaço e da imagem para que um fato seja alçado à condição de acontecimento e ganhe todas as mídias. Nesse sentido, os meios alimentam-se dos meios, a partir da hegemonia da televisão, que "age sobre os telespectadores comuns, mas também sobre as demais mídias" (Champagne, 1993, p. 63). A violência é notícia, mas o que é violência e quem detém o poder de nomeá-la? Tal definição de modo algum é sinônimo de consenso, muito pelo contrário. 
É importante lembrar, mesmo sem desenvolver aqui as implicações decorrentes, que o tema do poder abre espaço ao debate sobre as noções de legitimidade, legalidade, normas e leis, ordem, uso da força versus violência, as quais têm na justiça e nos operadores do direito atores privilegiados, mas não exclusivos, diante do poder de sua nomeação. A reflexão aqui vai em outra direção: o empiricamente vigente (ou seja, as representaçôes sociais que no dia a dia orientam as ações dos atores sociais) é tão ou mais importante que a ordem legalmente estabelecida (determinada por lei).

Violência, segurança pública e representações sociais

Os fenômenos da violência, ao serem enfocados pelos meios de comunicação de massa, invadem cotidianamente nossos sentidos com espetáculos que parecem querer sinalizar a barbárie, colocando-nos às vésperas de uma guerra civil. São imagens, discursos e narrativas que acabam por produzir um deslocamento nos conteúdos do imaginário social, por meio do qual o "mito do homem cordial" cede espaço à "lei do mais forte", compondo um quadro mental de intranquilidade e de caos, percebidos como representativos da contemporaneidade brasileira.

Nesse contexto, é tão urgente quanto difícil a tarefa de definir o que é violência. Dificuldades decorrentes de várias razões, entre as quais a presença no fenômeno de componentes de natureza objetiva tanto quanto subjetiva. Sob essa perspectiva, será parcial a abordagem de violência que se ativer aos chamados "dados objetivos" sem incorporar, além dos fatos e das estatísticas, a subjetividade das representaçôes sociais, orientadoras de conduta. Além disso, como enfatiza Michaud (1989), o que cada sociedade nomeia como violência varia no tempo e no espaço, segundo distintas representaçôes. Sob a dimensão teórica, ressaltar o aspecto relativo do fenômeno não é sinônimo de assumir um relativismo puro, a partir do qual tudo se equivale e cuja exacerbação leva ao irracionalismo, que inviabiliza a atividade científica. Pensando do ponto de vista empírico, as especificidades culturais apontam ao olhar sociológico a relatividade dos valores, implicando, necessariamente, distintas representaçōes da violência.

Ou seja, de um lado, não há uma definição em abstrato, que possa ser "aplicada" a qualquer sociedade. De outro, o relativismo não leva a lugar nenhum. Uma forma possível para contornar o impasse seria considerar (em termos de relativismo) a integridade, física e moral, da pessoa: toda vez 
que tal integridade fosse atingida poder-se-ia assumir que estaríamos em presença de um ato violento. É claro que aí também não se está isento de ambiguidades, pois cabem interpretações sobre o que seja, por exemplo, integridade moral e sobre os critérios para tal classificação. Pensando na relação objetivo/subjetivo, seria viável admitir que se poderia falar de violência sempre que a alteridade fosse desconsiderada, esquecida, desconhecida, negada. Em outras palavras, sempre que o outro fosse desconsiderado como sujeito e, em função disso, tratado como objeto, inviabilizando em última análise a interação social, fosse ela de natureza consensual ou conflituosa (cf. Wieviorka, 1997).

\section{Articulando mídia e segurança pública}

Considerando as representações sociais como matéria-prima do "fazer sociológico" e dado concreto a ser levado em conta pelo elaborador de políticas públicas, seria possível afirmar, arriscando algum exagero, que, quando se trata da segurança pública e da elaboração de políticas públicas de segurança, o fato importaria menos do que sua versão, já que esta orienta o agir dos atores sociais. Entretanto, em prol do equilíbrio, o mais sensato, talvez, seja dizer que interessaria tanto o fato, o acontecimento, como suas representações, que são igualmente parte de sua definição. Desse modo, entender por que a mídia produz certas representaçôes sobre violência ou segurança pública pode revelar-se mais pertinente do que se preocupar apenas em desmentir ou confirmar tal e qual representação.

Assim, importa entender as representaçôes acerca do caráter crescente e endêmico da violência, as quais ganham a forma de um clamor por segurança, entendida, esta, como sinônimo de um conjunto de medidas, ações e intervenções de ordem estatal que reduzam essa violência. Vozes se levantam reivindicando desde mais solidariedade e paz até o retorno a uma suposta idade da inocência, numa visão mística e mítica da sociedade. A mídia é um dos canais mais significativos a expressar tal clamor. Por meio de suas narrativas e discursos, argumenta-se em termos da existência de uma crise no sistema de segurança pública, imputada à carência e precariedade de recursos humanos e materiais e à baixa eficácia dos procedimentos, articulando causas estruturais a circunstâncias conjunturais. Outra constatação também recorrente diz respeito à quase homologia entre violência e medo: fala-se do crescimento de ambos, assim como de sua relevância no contexto urbano brasileiro, como realidades inseparáveis. 
Se em paralelo a tais diagnósticos alguma manifestação brutal de violência provoca estados de choque e/ou de comoção popular, reaviva-se o debate entre barbárie e civilização, com reivindicações em termos de solução. Nesses contextos, é comum o Estado responder na forma de algum plano emergencial, aí incluídas desde promessas de aumentos no repasse de recursos financeiros (condicionados a contrapartidas em termos de um efetivo plano de metas, práticas e ações específicas para redução da violência), até a proposta de mudanças que requerem a interferência no processo legislativo, com a produção de novas leis e/ou do aumento ou endurecimento das penas existentes, em uma espécie de lógica legiferante, que atribui os problemas à insuficiência de leis e as soluções à prevalência de um Estado punitivo. São medidas que visam a intervir atestando a eficácia da atuação policial e anestesiando o clima de medo e insegurança que, nesses contextos, toma conta da população. Medidas necessárias, algumas delas, mas insuficientes, se tomadas isoladamente.

Exemplos desse tipo ocorreram no final de 2007 no Distrito Federal, quando um motorista embriagado, e provavelmente drogado, e que participava de um "racha", provocou a morte de três mulheres ao se chocar em alta velocidade contra o carro em que elas se encontravam. A onda de protestos, passeatas e movimentos teve na mídia espaço privilegiado de expressão e, como resposta, um pacote antiviolência no trânsito. Em casos desse tipo, o caráter de "perecividade" do acontecimento, em sua vertente de notícia, pode também significar ausência de continuidade das políticas: passado o impacto do acontecimento, retomam-se os padrões anteriores de falta de efetividade, nada mudando. Ou seja, a notícia é uma mercadoria como outra qualquer, assim como a violência, a qual, com amplo poder de venda no mercado da informação, é transformada em objeto de consumo e faz com que a sua realidade passe a fazer parte do dia a dia mesmo daqueles que nunca a confrontaram diretamente. Exemplifico com dados de uma pesquisa sobre "Representaçōes Sociais da Violência no DF" (cf. Porto, 2002), apresentados no Gráfico1.

Outro exemplo é o Programa Nacional de Segurança com Cidadania Pronasci. Com recursos da ordem de 6,7 bilhões de reais, o programa (que articula medidas preventivas e de cunho social a ações de repressão) respondeu a situaçôes emergenciais e a manifestações de violência de caráter difuso, privado e estatal, protagonizado, neste último caso, pela violência policial.

Respostas de outra natureza vêm não do espaço público, mas de instâncias privadas. $\mathrm{O}$ medo e a sensação de insegurança são bons exemplos do que se pretende argumentar: bem maiores nos ricos condomínios fechados 
das megalópoles brasileiras do que na maioria das periferias dessas e das pequenas cidades, esses sentimentos fazem com que os moradores dos primeiros espaços se tranquem e se protejam, utilizando-se, para tanto, de todos os implementos que a moderna tecnologia produziu para a área da segurança. Em relação a esses locais, é comum circularem representações de pânico que pouco ou nada têm a ver com a realidade concreta da violência nesses espaços, "superprotegidos". Entretanto, a sensação de insegurança, por si só, "cria" a demanda por aumento de segurança. Aliada a representações de ineficiência ou ineficácia do sistema público de segurança, tal demanda induz à utilização do aparato de segurança em defesa de interesses particularistas, em detrimento do coletivo. Esse descrédito que leva a uma lógica do "salvese quem puder e como puder" é compatível com outra lógica que informa esse tipo de raciocínio, a de "fazer justiça com as próprias mãos", que leva cidadãos a se armarem e a se prepararem para a "guerra urbana". Descrédito que é, igualmente, o mote para alavancar a indústria bélica voltada para essa "guerra" e responsável pela produção do gigantesco aparato tecnológico de "proteção" que coloca o cidadão como agente de sua própria segurança.

GRÁFICO 1

Notícia e violência como mercadorias

"Em sua opinião, notícias sobre violência ajudam a vender jornais?":

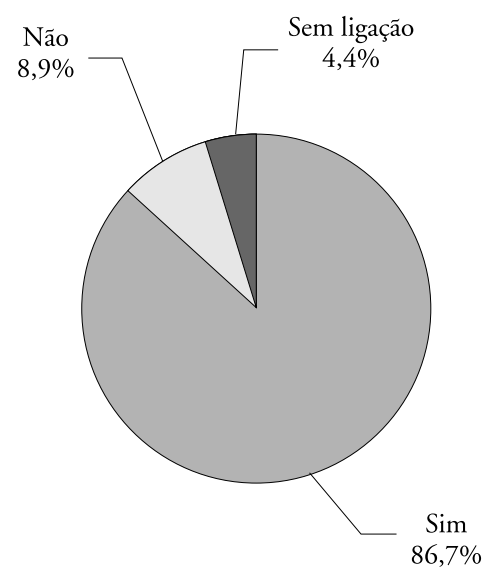

Fonte: Pesquisa sobre "Representaçōes Sociais da Violência no DF", 1998.

Essas novas representações da realidade estão se espraiando e abrindo espaço para a constituição de novas profissóes: assistindo a um jornal televisivo (março de 2008), surpreendi-me com o surgimento de uma nova profissão ou especialização: a de "consultor de segurança". O entrevistado e o 
repórter assim se exprimiram, com total naturalidade, ignorando e desconsiderando que o provimento de segurança é atribuição e prerrogativa do Estado, e condição de pacificação social (cf. Elias, 1969b) por meio da manutenção do monopólio de utilização da força física - violência legítima - em mãos do Estado. Esse exemplo aponta para consequências, ou efeitos, da articulação dessas duas representaçôes: a de uma situação de caos e guerra vigente nas metrópoles e a de demissão e ineficiência do Estado, conforme sentenciavam o repórter e o entrevistado do telejornal, afirmando que é nas falhas e fissuras da atuação do Estado que o setor privado se instala. Juntamente com a narrativa do consultor de segurança, outra área de atuação surge e somos apresentados ao "presidente de uma sociedade brasileira de blindagem", que relata, durante entrevista, as cifras astronômicas que a blindagem de um veículo representa, aliada aos problemas que, no médio ou longo prazo, o peso desses veículos acabará por representar para as garagens suspensas, não preparadas para a novidade.

Outro exemplo refere-se à questão da impunidade e ao tratamento dado a ela pela mídia. Não apenas a impunidade concretamente existente e testemunhada no cotidiano como prática corriqueira, mas também sua representação promovem o descrédito nas instituições, põem sob suspeição sua legitimidade e eficácia e situam-se acima da universalidade das normas jurídicas e dos códigos empíricos, que ela, a impunidade, substitui pelo particularismo e pelos privilégios (cf. Porto, 2002).

Na pesquisa sobre "Representações Sociais da Violência no DF", houve significativa convergência (nuançada pelo nível de escolaridade) entre os respondentes - 26,3\% - no sentido de apontar concordância em relação ao seguinte enunciado: "todos falam em direitos humanos, mas para acabar com a criminalidade a polícia tem mesmo que matar bandido". Em outra questão, para $69,2 \%$ dos respondentes, "como último recurso para manter a ordem, o policial deve usar o poder das armas" (cf. Porto, 2001a), como mostra o Gráfico 2.

Na prática, a prevalência da impunidade ou a onipresença de sua representação, como, por exemplo, na triste e corrente afirmação de que tudo "acaba em pizza", tende a colocar em ação uma espécie de lógica do "tudo ou nada", do "ele ou eu" e ainda do "se ele pode, por que não eu" que abre espaço à violência utilizada como forma de proteção.

Essas representações da criminalidade violenta disseminada na sociedade brasileira referem-se a atores tanto da sociedade civil como do aparato de segurança. Por exemplo, na pesquisa citada, merece registro a existência, por 
um lado, de um forte contingente (40,3\%) de moradores do DF prontos a identificar como criminosa a atuação do policial, em nada distinta daquela do bandido, considerando, especificamente, aquilo que, a rigor, investe o policial de seu poder legal de promotor da ordem, a saber, a utilização das armas. Por outro lado, é fato que essa forma "bandida" de o policial cumprir sua função tende a ser percebida como inevitável para boa parcela da população. Assim, 47,2\% dos pesquisados aceitaram que, dado o nível de criminalidade existente, seria impossível para a polícia apenas cumprir as normas legais (cf. Porto, 2001a).

GRÁFICO 2

Representaçôes da população sobre como garantir lei e ordem

"Para acabar com o crime a polícia tem que matar bandido":

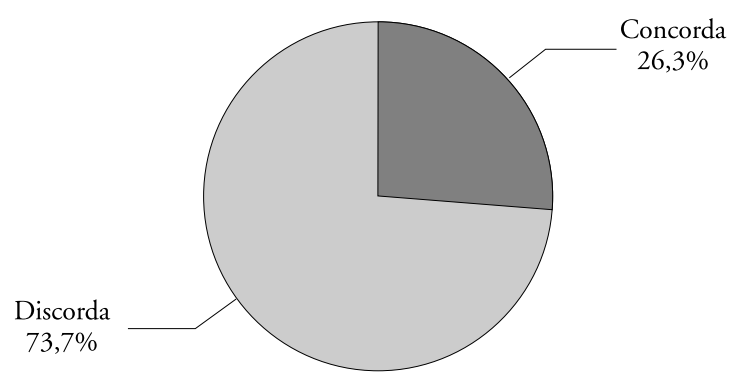

"Como último recurso para garantir a ordem social, o policial deve usar o poder das armas":

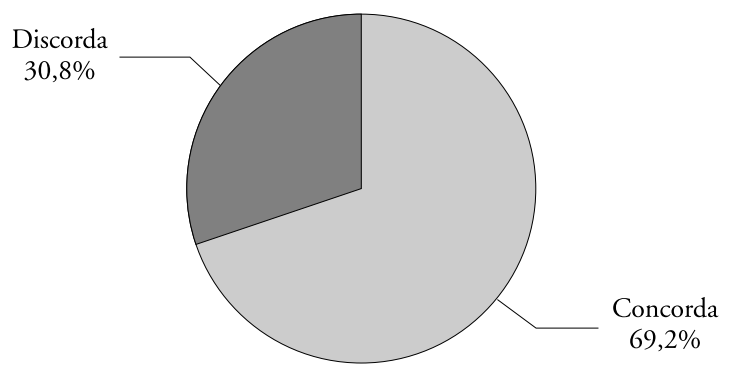

Fonte: Pesquisa sobre "Representações Sociais da Violência no DF”, 1998. 
GRÁFICO 3

Legalidades

"A polícia é igual ao bandido, não pensa duas vezes para atirar":

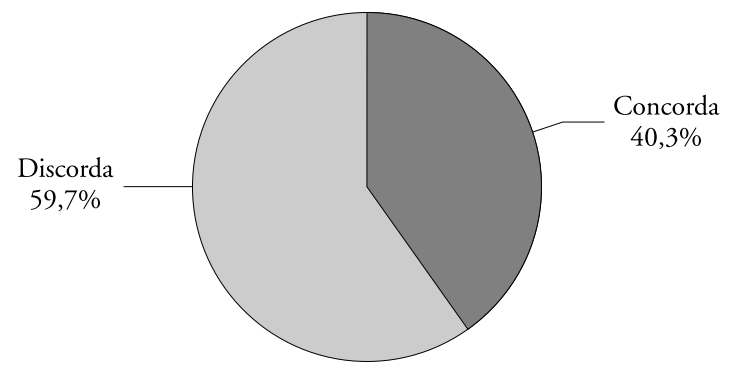

"A criminalidade chegou a tal ponto que é absurdo a polícia cumprir as normas legais":

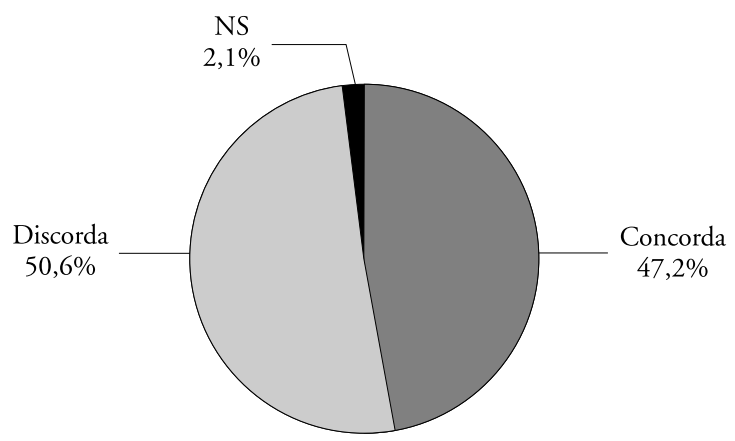

Fonte: Pesquisa sobre "Representaçôes Sociais da Violência no DF", 1998.

Entre as várias facetas da impunidade tratadas cotidianamente pelo noticiário, uma das que mais chama a atenção diz respeito à violência policial, midiaticamente apresentada a partir de narrativas, acontecimentos e versões submetidos a uma seleção que produz alguns destes como notícia, ao mesmo tempo em que mantém outros no esquecimento.

Se, de um lado, os policiais são continuamente apontados como fonte de condutas violentas, transgressoras e violentadoras dos direitos humanos, de outro são, seguidas vezes, demandados e cobrados para agir com mais eficiência, inclusive com utilização de violência.

Respondendo a esse fenômeno, as elites policiais, entrevistadas para outra pesquisa também desenvolvida por mim no DF (cf. Porto, 2004), consideram a sociedade brasileira violenta e avaliam a ação policial como desdobramento, efeito, consequência da violência social, e como resposta às expectativas e aos anseios dessa mesma sociedade. Como transparece neste depoimento de um dirigente policial: 
[...] Então, a expectativa da própria sociedade é do policial violento [...]. Quantas e quantas vezes a gente vê a mãe, que o filho não quer comer: olha, se não comer, eu chamo o guarda. Então, o mecanismo repressivo é uma coisa que está também num inconsciente coletivo [...] (Porto, 2004, p. 138).

São contextos que parecem deflagrar uma reciprocidade perversa entre sociedade civil e organizaçôes policiais, em função da qual a polícia tende a orientar condutas violentas a partir do que supóe que a sociedade espera dela como responsável pela lei e pela ordem. Essa lógica, não isenta de ambiguidades, faz com que a sociedade movida pelo combustível do medo e da insegurança cobre sempre mais e mais do policial: rapidez, eficiência e agilidade, fazendo dele um herói, se sua função de garantidor da ordem for por ela avaliada como bem-sucedida, ou um bandido, caso dê errado (Idem).

Ainda com relação à questão da impunidade, dois fatos recentes ocorridos no DF são significativos. No primeiro, como noticiado em 2 de dezembro de 1999 pelo Correio Braziliense, jornal de maior circulação na cidade (com cerca de 70 mil exemplares), um confronto entre policiais e manifestantes registrou um dos episódios mais truculentos da história da cidade: uma pessoa morta e 38 feridas (entre as quais duas perderam a visão) depois que 146 policiais militares avançaram sobre cerca de seiscentos servidores públicos da Novacap, que reivindicavam melhores salários. Quase oito anos depois, nenhum culpado pela violência foi condenado pela justiça (cf. Correio Braziliense, 29/07/2007). No segundo, depois da deflagração de uma crise na cúpula da segurança pública, no início do mês de março de 2008, o comandante geral da Polícia Militar foi destituído do cargo, acusado de improbidade administrativa e impunidade com relação a alguns de seus comandados. Conforme o relato do Correio Braziliense (13/03/2008): "Um terço das sindicâncias instauradas desde 2003 não estão até então encerradas. Hoje, 1.873 processos estão parados na corregedoria. Dos 816 inquéritos policiais militares concluídos entre 2005 e 2007, 260 eram casos de lesões corporais cometidos por militares". As denúncias incluíam o envolvimento com bandidos, venda de armamentos e até homicídio. A crise se acirrou e teve seu ápice durante o carnaval de 2008, quando cenas de violência policial foram manchete dos principais noticiários televisivos e jornais impressos. Se os problemas vinham de longa data, apenas tiveram desfecho quando as rotinas de produção jornalística pautaram o assunto, que ganhou visibilidade, transformando então o fato em acontecimento e ganhando contornos de problema político. Antes que a crise na segurança 
pública se transformasse em combustível de insegurança social e política, a resposta veio com a destituição do comandante geral da polícia militar. Articulação entre fato, acontecimento, notícia, apresentação, representação; solidariedade entre representações e práticas.

Em outra direção estaria o episódio do "ônibus 174", tragédia já famosa e transformada em filme pelo diretor do hoje igualmente famoso Tropa de elite. Nesse episódio, chama a atenção o fato de que todo o desenrolar da trama/drama foi televisado (se assim se pode dizer) e, no único momento em que a mídia abandona a cena, durante o percurso em que o sequestrador é levado preso em um carro de polícia, o desfecho é trágico, com sua morte. Nesse acontecimento, como em outros envolvendo a mídia, a visibilidade é algo apenas compatível com contextos democráticos e de liberdade de expressão, independentemente de se concordar ou não com o sensacionalismo que envolveu a prática midiática. Sob esse prisma, é fundamental ter em mente o caráter das relaçōes entre mídia e democracia, seja no sentido de apontar os entraves que se colocam à atuação da mídia em regimes de exceção - o período de vigência do regime ditatorial no Brasil pós-golpe militar de 1964 é, sob esse aspecto, exemplar -, seja, inversamente, para mostrar o papel central desempenhado pela mídia no sentido de contribuir para a transparência e a visibilidade requeridas na vigência democrática. No contexto dos movimentos pró-redemocratização brasileira, nos anos de 1980, setores da mídia somaram-se a distintos atores da sociedade civil nas reivindicaçôes pelo Estado de direito, ao lado das demandas pela garantia de respeito aos direitos humanos, às liberdades individuais e ao acesso à justiça para segmentos sociais "esquecidos" pelos braços da lei, para mencionar apenas alguns componentes dos processos de constituição da cidadania que, de algum modo, estão articulados ao tema deste artigo. Esses são exemplos que configuram o caráter plural e dinâmico do campo midiático, entrecortado não apenas por distintas abordagens teóricas mas caracterizado também por processos e rotinas produtivas igualmente informados por múltiplas ideologias e interesses econômicos, socioculturais e políticos.

No que diz respeito ao tema específico deste texto, muitos são os estudos que se propõem a buscar relações de causalidade entre violência e mídia. Embora quase todos estejam prontos a admitir a existência dessa relação, não conseguem demonstrá-la, pela própria complexidade envolvida. Entretanto, apesar de esse não ser o enfoque aqui privilegiado, buscando a inserção no debate e com base em texto anterior (cf. Porto, 2002), pode-se afirmar que os meios de massa, a depender de seus conteúdos, se não são 
diretamente responsáveis pelo aumento da violência e da criminalidade, funcionam, quando menos, como um canal de estruturação de sociabilidades violentas, já que neles a violência é, não raro, apresentada como um comportamento valorizado. Nos dizeres de Michaud,

[...] a violência na mídia, que ela seja estilizada ou não, que seja ficção ou parte dos telejornais da atualidade, serve, de uma certa maneira, a um descarregar-se, distenderse, dar livre curso aos sentimentos através do espetáculo. As cenas de violência são um sintoma da nervosidade da sociedade. Podem não tornar as crianças mais violentas, mas certamente contribuem para excitá-las (1996, p. 136).

As várias mediações entre causas e efeitos da violência não parecem ter sido consideradas pelos respondentes da pesquisa "Representações Sociais da Violência no DF", a cujos dados volta-se mais uma vez (cf. Porto, 2002). Os respondentes estabelecem uma relação causal direta entre exposição à violência e aumento da criminalidade; 78,6\% deles afirmaram que a difusão da violência pela mídia contribuiria para aumentar a criminalidade.

\section{GRÁFICO 4}

\section{Violência e criminalidade}

"A difusão da violência nos meios de comunicação pode contribuir para o aumento da criminalidade social?":

\begin{tabular}{lll}
\hline IDADE & SIM \% & NĀO\% \\
\hline 15 a 24 & 74,0 & 26,0 \\
25 a 44 & 80,1 & 19,9 \\
acima de 45 & 82,6 & 17,4 \\
\hline TOTAL & 78,6 & 21,4 \\
\hline
\end{tabular}

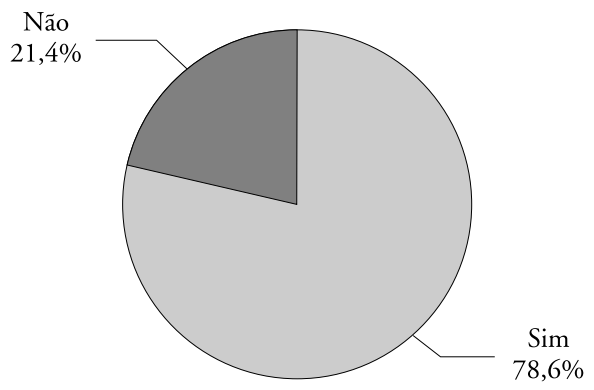


$\mathrm{Na}$ distinção por faixa etária, apenas os jovens revelam mais condescendência em relação ao potencial indutor de violência pela mídia. Nessa faixa etária, 26\% dos entrevistados não relacionam exposição à violência na mídia e aumento de criminalidade, contra $19 \%$ e $17 \%$, respectivamente, das demais faixas de idade, ou seja, entre 25 e 44 anos, e mais de 45 anos.

Além disso, como indica o Gráfico 5, há, no geral, uma condenação da mídia, tendência que parece solidária àquela de diabolizar seu papel, minimizando o fato de que o consumo desses meios alimenta os conteúdos mostrados. Se a mídia é frequentemente julgada, posta na berlinda e condenada, ela também julga. Aliás, sob esse aspecto, é unânime a representação segundo a qual os meios funcionam como um tipo de tribunal do júri, antecipando ou dando o tom, em termos da condenação ou absolvição de um suspeito. Os dados, e as representações que eles expressam, são de uma desconcertante atualidade, passados dez anos da realização da pesquisa.

\section{GRÁFICO 5}

Se a mídia é julgada, ela também julga

"Os meios de comunicação de massa influenciam a opinião pública no julgamento de uma pessoa que cometeu determinado crime?”:

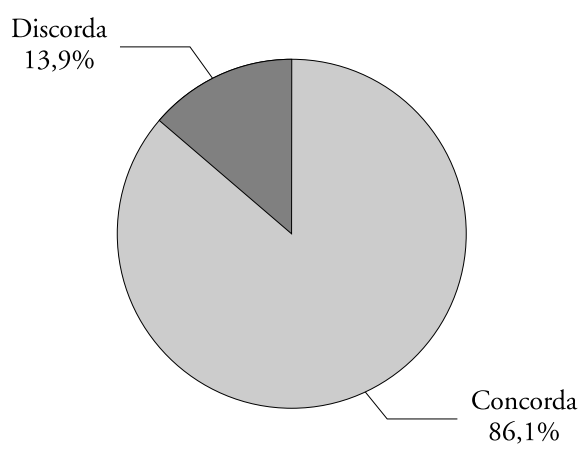

Fonte: Pesquisa sobre “Representações Sociais da Violência no DF”, 1998.

Sob a ótica do jornalismo investigativo, que se apresenta e se representa, por vezes, como juiz, polícia, censor, são enormes as tensões envolvendo jornalismo, mídia e crime. Nesse contexto, tornaram-se famosos casos emblemáticos de jornalistas assassinados durante o trabalho investigativo. Em meados de 2007, mais uma vez o Correio Braziliense, em matéria relacionada à área de segurança pública, publicou durante dois ou três meses uma 
série de reportagens sob o título "Tráfico, extermínio e medo", expondo aspectos centrais da questão da violência e da fragilidade a que está exposta a população do entorno de Brasília, com as consequências decorrentes para o conjunto da região. O próprio jornal e a região viram-se no centro do redemoinho e como pivôs das atenções nacionais e internacionais quando um dos jornalistas responsáveis pelas reportagens foi baleado, justamente em uma cidade goiana do entorno - Cidade Ocidental -, em meio ao trabalho de investigação. Antes mesmo de concluir o inquérito, a clara tentativa de assassinato chegou a ser tratada pela polícia goiana como caso de assalto. Estaria embutida aí a intenção de censurar a mídia?

Assim, a censura apresenta-se como uma via de mão dupla: no caso da mídia, se esta pode chegar a ser censurada (por meio de relações de poder, mais do que pela via formal de proibição de publicar algo), ela igualmente censura, quando por exemplo se cala sobre os comerciais de bebidas, cigarros, carros e velocidade, associando de forma mais ou menos velada tais mercadorias e seus consumidores a determinados estilos de vida, social e simbolicamente valorizados. O cumprimento pro forma da legislação - se beber não dirija; fumar é prejudicial à saúde - funciona, paradoxalmente, quase como um reforço à publicidade, já que as advertências politicamente corretas atestam o "dever cumprido". É bom insistir que com isso não se está, aqui, advogando que a ciência e os estudiosos se invistam da função denunciativa, de proclamar o certo e o errado em matéria de política cultural, de censura etc. Mas aponta, ao contrário, para algo não normativo, que reafirma o quanto as políticas de segurança pública poderiam se beneficiar ao considerar o que as representaçoes sociais produzidas pela mídia afirmam. Buscando melhor captar a cena política, as tensões, o jogo de forças, a disputa pelo monopólio da informação, interno e externo ao campo midiático, os formuladores dessas políticas poderiam construir de modo mais autônomo, e portanto menos pautadas pela mídia, as prioridades da área.

E o que ocorre quando a segurança pública se transforma, ela mesma, em mídia? Isso vem acontecendo em alguns setores da polícia. No DF, por exemplo, em busca talvez de atestar maior credibilidade à sua atuação, policiais estão produzindo jornais que, na contramão da cobertura da grande imprensa (que evita mostrar imagens chocantes em situações de violência), estampam em suas manchetes imagens de grande crueldade e realismo, com corpos mutilados, deformados, decompostos. Se eventualmente esse trabalho significar a captura de bandidos, mesmo com a sua morte, as manchetes e os furos das reportagens não seriam a reafirmação de representações 
recorrentes no espaço da segurança pública, segundo as quais "bandido bom é bandido morto"?

São questōes e afirmações expressivas de múltiplas mediações articuladoras das relações mídia/violência e representaçôes sociais.

Uma tentativa de compreensão desses fenômenos, sugerida mais como objeto de reflexão do que como perspectiva de conclusão, poderia estar no fato de que as representações sociais, não sendo

[...] versões objetivas, nem construções imaginárias, expressam uma prática, organizando-a. Ao fazê-lo, expressam igualmente as ambiguidades, contradiçóes, oposições de interesses que se traduzem no nível da própria realidade, e não como consequência da inversão do real pelo simbólico. $\mathrm{O}$ caráter arbitrário do símbolo não é necessariamente sinônimo de sua falsidade. As formas de representação social não se produzem no abstrato, mas têm na realidade vivida sua matéria-prima. O fato é que essa realidade nem sempre se apresenta de forma clara, transparente. É uma realidade contraditória que vela e revela, simultaneamente. Além de referida a uma prática social contraditória, a reflexão simbólica, objeto da representação de uma dada categoria, se constrói em referência a outras práticas simbólicas, fundadas em visões de mundo complementares, contraditórias ou mesmo antagônicas à sua própria (Porto, 1989, pp. 275-276).

Nesse sentido, considerar o que dizem as representações poderia ser um caminho para reduzir a distância entre polícia e sociedade; entre as políticas e planos de segurança pública e as expectativas e representaçôes sociais, produzidas por aqueles que direta ou indiretamente se beneficiam ou sofrem as consequências dos acertos ou desacertos dessas mesmas políticas. Captar os ecos das representações pode se constituir em mecanismo importante para reverter determinadas práticas, tanto no âmbito da segurança pública como no da sociedade civil.

\section{Referências Bibliográficas}

Bourdieu, Pierre. (1984), Questions de sociologie. Paris, Minuit. . (1996), Sur la télévision. Paris, Raisons d'Agir.

Bourdieu, Pierre \& Wacquant, Loïc. (1992), Réponses. Paris, Seuil.

CAREY, James. (1973), “A cultural approach in communication”. Urbana-Champagn, Institute of Communications Research, University of Illinois, mimeo. (Publicado posteriormente em Communication, 2, 1975, pp. 1-22.) 
(1989), Communication as culture: essays on media and society. Boston, Unwin Hyman. (Reeditado em Nova York/Londres, Routledge, 1992.)

Champagne, Patrick. (1993), “La vision médiatique”. In: Bourdieu, Pierre (org.), La misère du monde. Paris, Seuil.

CoHn, Gabriel (org.). (1987), Comunicação e indústria cultural. São Paulo, T. A. Queiróz.

Comunicação \& Política. (1994/1995), “Mídia, drogas e criminalidade”, v. 1, n. 2, dez./mar.

ELIAS, Norbert. (1969a), La civilisation des moeurs. Paris, Calmann-Levy. (1969b), La dynamique de l'Occident. Paris, Calmann-Levy.

Giddens, Antony. (2003), A constituição da sociedade. São Paulo, Martins Fontes. JoDelet, Denise. (1984), "Représentation sociale: phénomènes, concept et théorie". In: Farr, R. M. \& Moscovici, S. (eds.), Social representations. Cambridge/Paris, Cambridge University Press/Maison des Sciences de l'Homme. . (2001), "Representaçôes sociais: um domínio em expansão”. In: (org.), As representaçôes sociais. Rio de Janeiro, Editora da Uerj.

Johnson, Richard. (2000), “O que é, afinal, estudos culturais?”. In: Silva, Tomaz Tadeu da (org. e trad.), O que é, afinal, estudos culturais? Belo Horizonte, Autêntica.

Les Cahiers de la Sécurité Intérieure. (1995), Médias e Violence. Paris, IHESI, 20 ( 20 trimestre).

Lima, Venício A. de. (2001), Mídia, teoria e política. São Paulo, Editora Fundação Perseu Abramo.

Michaud, Yves. (1989), Violence et politique. Paris, Gallimard. . (1996), La violence apprivoisée. Paris, Hachette.

Minayo, Maria Cecília de Souza. (1994), "O conceito de representações sociais dentro da sociologia clássica”. In: Jovchelovitch, S. \& GuARESCHI, P. (orgs.), Textos em representaçôes sociais. Petrópolis, Vozes.

Moscovici, Serge. (1984), “The phenomenon of social representations”. In: FARR, R.

M. \& Moscovici, S. (orgs.), Social representations. Cambridge/Paris, Cambridge University Press/Maison des Sciences de l'Homme.

. (1989), "Des représentations collectives aux représentations sociales: éléments pour une histoire”. In: JodelEt, D. (org.), Les représentations sociales. Paris, Presses Universitaires de France.

. (1994), "Prefácio". In: Jovchelovitch, S. \& Guareschi, P. (orgs.), Textos em representaçôes sociais. Petrópolis, Vozes.

. (2003), Representaçôes sociais, investigaçôes em Psicologia Social. Petrópolis, Vozes.

Muhlmann, Géraldine. (2008), "Presse et démocracie". In: Park, Robert E. et al. (orgs.), Le journaliste et le sociologue. Paris, Seuil. 
Peralva, A. \& Macé, E. (2002), Médias et violences urbaines: débats politiques et construction journalistique. Paris, IHESI, La Documentation Française.

PORTO, Maria Stela Grossi. (1989), “A produção ideológica como produção material”. In: Figueiredo, Vilma (coord.), Estado, sociedade e tecnologia agropecuária. Brasília, Editora Pax.

. (2001a), "Violência e segurança: a morte como poder?". In: Oliveira, Dijacy de et al. (orgs.), Violência policial: tolerância zero? Brasília/Goiânia, MNDH/UFG. . (2001b), "Impunidade, avesso da reciprocidade". Sociedade e Estado, 16 (1/ 2): 336-349, jan./dez.

. (2002), "Violência e meios de comunicação de massa na sociedade contemporânea”. Revista Sociologias, Porto Alegre, 4 (8): 152-171, jul./dez.

. (2004), "Polícia e violência: representaçôes sociais de elites policiais do Distrito Federal”. São Paulo em Perspectiva. Fundação Seade. São Paulo, 18 (1): 132141, jan./mar.

Proulx, Serge. (1995), "Les perspectives d'analyse des médias: des effets aux usages". Les Cahiers de la Sécurité Antérieure, Paris, IHESI, 20 (20 trimestre).

RevisTA DA USP. (1991), "Dossiê violência”, São Paulo, mar./abr./maio.

Ramos, Silvia \& PaIva, Anabela. (2007), Mídia e violência: novas tendências na cobertura de criminalidade e segurança no Brasil. Rio de Janeiro, Iuperj.

Touraine, Alain. (1997), "Faux et vrais problèmes". In: Wieviorka, M. (org.), Une societé fragmentée? Le multiculturalisme en débat. Paris, La Decouverte/Poche.

Wieviorka, Michel. (2006), Em que mundo viveremos? São Paulo, Perspectiva. . (2005), La violence. Paris, Pluriel Hachette Litterátures.

. (2002), La diférence, identités culturelles: enjeux, débats et politiques. Paris, Éditions de l'Aube. . (1997), "O novo paradigma da violência". Tempo Social, São Paulo, 9 (1): 542, maio.

Wolf, Mauro. (1987), Teorias da comunicação. Lisboa, Presença. Wolton, Dominique. (2004), Pensar a comunicação. Brasília, Editora UnB. 


\section{Resumo}

Mídia, segurança pública e representações sociais

$\mathrm{O}$ artigo tem como objetivo pensar a natureza complexa das relaçōes entre mídia e segurança pública, as quais, como realidades não acabadas em si mesmas, conformam um campo em constante tensão. Argumenta-se que nas modernas democracias contemporâneas a mídia se constitui em instrumento relevante de elaboração de representações sociais, que, por sua vez, para além de seu caráter falso ou verdadeiro, são veículos privilegiados para a produção e a reprodução de crenças e valores, com função pragmática enquanto orientadoras de conduta de distintos atores sociais. Defende assim a relevância de considerar que tais representaçôes (aí incluídas, portanto, aquelas produzidas pela mídia) poderiam ser levadas em consideração, como subsídio, quando da formulação de políticas para a área da segurança pública. Como suporte empírico, o artigo se utiliza de exemplos e consideraçôes voltados à análise do contexto do Distrito Federal.

Palavras-chave: Mídia; Representações sociais; Violência policial; Segurança pública; Políticas públicas; Distrito Federal.

\section{Abstract}

The media, public security and social representations

The article's objective is to reflect on the complexity of the relations between the media and public security, which as forever incomplete realities generate a field of constant tensions. It argues that in contemporary modern democracies the media comprises an important instrument in the elaboration of social representations, which, in turn, irrespective of their truth or falsity, are key vehicles for the production and reproduction of beliefs and values, performing the pragmatic function of guiding the conduct of a wide variety of social actors. It therefore argues for the importance of taking these representations (including those produced by the media) into consideration as background material during the formulation of policies in the area of public security. In empirical support of this argument, the article uses examples and analyses relating to the context of Brazil's Federal District.

Keywords: Media; Social representations; Political violence; Public security; Public policies; Federal District.

Texto recebido em 19/6/ 2008 e aprovado em 26/01/ 2009.

Maria Stela Grossi Porto é professora do Departamento de Sociologia do ICS, UnB. E-mail: msgrossi@un b.br. 